J. Lake Sci. (湖泊科学), 2013, 25(2): 188-198

http: //www. jlakes.org. E-mail : jlakes@niglas.ac.cn

(C) 2013 by Journal of Lake Sciences

\title{
沉水植物生态修复对西湖细菌多样性及群落结构的影响"
}

\author{
李琳琳 $^{1,2}$, 汤祥明 ${ }^{2 * *}$, 高 光 $^{2}$, 邵克强 ${ }^{2}$, 龚志军 ${ }^{2}$, 陈 丹 $^{2}$, 张云华 ${ }^{1 * *}$ \\ ( 1 : 安徽农业大学生命科学学院,合肥 230036) \\ (2: 中国科学院南京地理与湖泊研究所湖泊与环境国家重点实验室,南京 210008)
}

\begin{abstract}
摘 要: 沉水植物的重建是湖泊富营养化修复的关键措施之一. 本研究利用在杭州西湖进行的沉水植物生态修复工程, 应用基于聚合酶链式反应的变性梯度凝胶电泳 (PCR-DGGE) 及分子克隆等手段, 研究种植蕰草和苦草对水体中细菌多样 性及群落结构的影响. 未进行沉水植物生态修复的湖区细菌以 Bacteroidetes ( $42.9 \%) 、$ Betaproteobacteria (30.8\%) 和 Verrucomicrobia $(14.3 \%)$ 为主. 而种植蕰草和苦草后, Bacteroidetes 所占的比例分别减少到 $12.7 \%$ 和 $5.3 \%$; Betaproteobacteria 则 分别提高到 $52.4 \%$ 和 $59.5 \%$; Alphaproteobacteria 由 $4.4 \%$ 分别提高到 $19.0 \%$ 和 $12.8 \%$. 种植蕰草后 Verrucomicrobia 所占比 例大幅降低, 而种植苦草对 Verrucomicrobia 的影响不大. 沉水植物修复不仅可以改善水质, 同时也可以显著提高水体中细 菌的多样性,改变细菌的群落结构.
\end{abstract}

关键词: 沉水植物;生态修复; 细菌多样性;变性梯度凝胶电泳; 克隆文库;西湖

\section{Influence of submerged vegetation restoration on bacterial diversity and community com- position in West Lake}

LI Linlin ${ }^{1,2}$, TANG Xiangming ${ }^{2}$, GAO Guang ${ }^{2}$, SHAO Keqiang ${ }^{2}$, GONG Zhijun ${ }^{2}$, CHEN Dan $^{2}$ \& ZHANG Yunhua ${ }^{1}$

(1: School of Life Science, Anhui Agricultural University, Hefei 230036, P. R. China)

(2: State Key Laboratory of Lake Science and Environment, Nanjing Institute of Geography and Limnology, Chinese Academy of Sciences, Nanjing 210008, P. R. China)

\begin{abstract}
Reconstruction of submerged vegetation is one of the key measures of eutrophication remediation. Using polymerase chain reaction-denaturing gradient gel electrophoresis (PCR-DGGE) and clone library analysis, we studied the impact of planting Potamogeton crispus and Vallisneria natans on bacterial diversity and community composition in West Lake, Hangzhou, China. Bacteroidetes $(42.9 \%)$, Betaproteobacteria $(30.8 \%$ ) and Verrucomicrobia (14.3\%) dominated in the water column from lake areas without submerged macrophytes. On the contrast, the proportion of Bacteroidetes reduced to $12.7 \%$ and 5.3\%, respectively, after planting Potamogeton crispus and Vallisneria natans. Meanwhile, Betaproteobacteria increased to 52.4\% and 59.5\% , and Alphaproteobacteria increased from $4.4 \%$ to $19.0 \%$ and $12.8 \%$, respectively. The proportion of Verrucomicrobia reduced substantially after planting Potamogeton crispus, but varied little after planting Vallisneria natans. This study indicates that submerged macrophytes can not only improve water quality, but also increase bacterial diversity, and shape bacterial community composition significantly.
\end{abstract}

Keywords: Submerged vegetation; ecological restoration; bacterial diversity; DGGE; clone library; West Lake

近年来, 湖泊富营养化已成为世界范围内一个突出的环境问题 ${ }^{[1-3]}$. 随着富营养化的加剧, 湖泊中常暴 发藻类水华, 水生植物急剧减少, 甚至消失. 而大型水生植物, 特别是沉水植物, 能吸收利用水体中的营养物

* 国家水体污染控制与治理科技重大专项项目(2009ZX07106-002)、江苏省自然科学基金项目 (BK2011878) 和中国 科学院南京地理与湖泊研究所青年基金项目 (NIGLAS2011QD13) 联合资助. 2012-07-27 收稿; 2012-09-14 收 修改稿. 李琳琳, 女, 1989 年生, 硕士研究生; E-mail : lin36999@ 126. com.

** 通信作者; E-mail : xmtang@ niglas. ac.cn; yunhua9681@163.com. 
质, 合成自身生长发育所需要的物质, 有效地降低水体中的营养盐浓度, 同时与藻类竞争营养盐, 抑制 “藻 华”的暴发. 因此,沉水植物的恢复往往是湖泊富营养化修复的主要措施之一 ${ }^{[4-6]}$.

在水生态系统中, 微生物是极为敏感并易受环境影响的生物类群. 它们不仅是系统中生物量的重要组 成部分, 而且影响着物质循环和营养传递过程 ${ }^{[7]}$. 鉴于细菌在水生态系统中的重要作用及其对生态系统的 变化反应迅速等特点, 在生态修复过程中, 细菌的丰度、群落结构及多样性等的变化可以作为评判生态修复 效果的重要指标 ${ }^{[8-9]}$.

杭州西湖是我国著名的风景旅游湖泊, 也是一个浅水型城市富营养化湖泊, 水域面积 $5.6 \mathrm{~km}^{2}$, 平均水 深仅 $1.56 \mathrm{~m}$. 湖水的总氮 $(\mathrm{TN})$ 和总磷 (TP) 分别为 2.204 和 $0.125 \mathrm{mg} / \mathrm{L}$, 平均透明度仅为 $46 \mathrm{~cm}^{[10]}$. 经过一 系列整治工程后, 水质得到了一定程度的改善, 如北里湖 TN 和 TP 分别为 1.930 和 $0.041 \mathrm{mg} / \mathrm{L}$, 但湖泊富营 养化问题依然没有解决 ${ }^{[11]}$. 目前, 关于西湖细菌的研究主要集中在对西湖水体及沉积物中可培养细菌方 面 ${ }^{[10,12-14]}$, 但天然水环境中的微生物仅有 $0.001 \% \sim 3 \%$ 可以被分离培养 ${ }^{[15]}$, 利用传统的平板菌落计数方法 不能获取水体中比较真实的细菌丰度信息, 更无法了解特定生态修复措施是如何导致生境中微生物种群组 成的变化.

近些年, 随着分子生物技术的迅速发展, 基于原核生物 $16 \mathrm{~S} \mathrm{rRNA}$ 基因的聚合酶链式反应一变性梯度凝 胶电泳 (PCR-DGGE) 及克隆文库等技术, 已广泛应用于湖泊生态系统的微生物群落结构研究 ${ }^{[16-21]}$. 湖泊生 态修复研究表明, 沉水植物可显著改变水体中细菌的多样性 ${ }^{[22-23]}$, 但沉水植物对水体中细菌群落组成的影 响却少有报导. 本文采用 PCR-DGGE 和克隆文库相结合的方法, 研究了杭州西湖沉水植物生态修复对水体 细菌多样性及群落结构的影响, 以期为富营养化湖泊生态系统修复机制提供理论依据.

\section{1 材料和方法}

\section{1 实验设计及采样地点}

为了改善西湖水质, 实施了以沉水植被恢复为主的生态修复工程. 实验围隔建在西湖北面的北里湖 $\left(30^{\circ} 15^{\prime} 26^{\prime \prime} \mathrm{N}, 120^{\circ} 8^{\prime} 16^{\prime \prime} \mathrm{E}\right.$; 图 1), 由聚乙烯布围成, 共 6 个, 每个围隔 $6 \mathrm{~m}$ 长、4 m 宽、 $1.7 \mathrm{~m}$ 深. 围隔底部先铺 上竹排再加上西湖底泥, 厚约 $40 \mathrm{~cm} .2011$ 年 1 月在 $1^{\#} \sim 3^{\#}$ 围隔种植淔草 (Potamogeton crispus), $4^{\#} \sim 6^{\#}$ 围隔 撒播苦草(Vallisneria natans) 块茎(图 1). 本次试验采样点分别设在 6 个围隔 ( $1^{\#} \sim 3^{\#}$ 围隔记作蕰草处理; $4^{\#} \sim 6^{\#}$ 围隔记作苦草处理) 及围隔外北里湖未进行生态修复的湖区 $7^{\#} \sim 9^{\#}$ (记作无草对照). 4 月底采样时 $1^{\#} \sim 3^{\#}$ 围隔菹草繁茂, 株高约 $1.2 \mathrm{~m}$, 覆盖度达到 $100 \% ; 4^{\#} \sim 6^{\#}$ 围隔苦草长出约 $15 \mathrm{~cm}$, 覆盖度约为 $50 \%$.
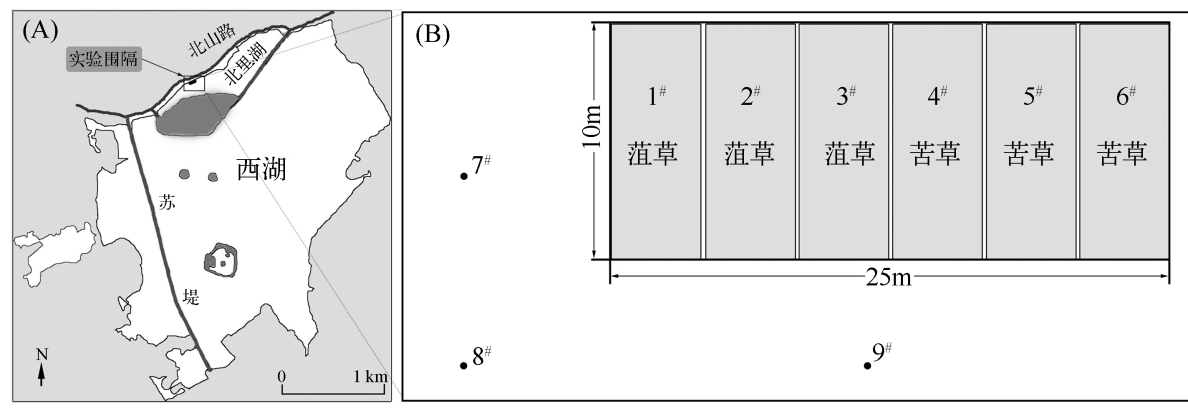

图 1 杭州西湖生态修复工程位置、围隔设置及采样点

Fig. 1 Location of ecological restoration project, design of enclosures and sampling sites in West Lake, Hangzhou

\section{2 样品的采集及处理}

于 2011 年 4 月 29 日, 用采水器采集每个围隔内及对照点的表层水样 (水下约 $50 \mathrm{~cm}$ 处) 各 $5 \mathrm{~L}$. 水样分 成 3 个部分: (1) 取 $250 \mathrm{ml}$ 水样, 现场用手持式真空筡于 $0.2 \mu \mathrm{m}$ 孔径的聚碳酸酯滤膜上过滤, 然后用灭过 菌的离心管收集滤膜, 置于 $-20^{\circ} \mathrm{C}$ 保存, 一周内进行 DNA 提取及细菌群落结构分析. (2) 另取 $46 \mathrm{ml}$ 水样装 
人灭过菌的离心管中, 管中预先加人了用 $0.2 \mu \mathrm{m}$ 孔径的滤膜过滤后的无颗粒甲醛溶液 $4 \mathrm{ml}$ (甲醛的终浓度 为 $2 \% \mathrm{~V} / \mathrm{V}$, 体积比), 样品置冰盒中运回实验室后置冰箱 $4{ }^{\circ} \mathrm{C}$ 保存, 一周内进行细菌丰度测定. (3) 其余水样 置于预先洗净的塑料桶中送到实验室直接用于水样化学及生物指标分析.

\section{3 理化参数的测定}

采样点水体的透明度 (SD) 用透明度盘现场测定. 水深用便携式测深仪 (奥地利 UWITEC 公司) 现场测 定. 水温、 $\mathrm{pH}$ 、溶解氧 (DO)、浊度及叶绿素 $\mathrm{a}$ ( Chl. a) 的含量用多参数水质测定仪 (YSI6600V2, USA) 现场测 量. 总磷、总氮、溶解性总氮 (DTN)、溶解性总磷 (DTP) 含量的分析参照《湖泊富营养化调查规范》 ${ }^{[24]}$. 悬浮 物含量 (SS) 为水样经 Whatman GF/F 膜过滤后将滤膜在 $105^{\circ} \mathrm{C}$ 烘干 $4 \mathrm{~h}$ 至恒重后的质量 ${ }^{[24]}$; 称重后的滤膜 放人马弗炉, 在 $550^{\circ} \mathrm{C}$ 下灼烧 $3 \mathrm{~h}$ 至恒重后再次称重, 两次质量之差即为悬浮物中有机质的含量.

\section{4 细菌计数}

采用 DAPI 染色后表面荧光显微镜直接计数的方法 ${ }^{[25]}$. 将上述甲酫固定的水样用无菌水稀释一定倍 数, 用核酸染料 DAPI 染色, 于表面苂光显微镜在 $16 \times 100$ 放大倍数下观察计数, 每个样品不少于 20 个视 野, 再将视野里的细菌个数转换成每毫升细菌数, 即为细菌丰度.

\subsection{DNA 提取及 PCR-DGGE 分析}

水样细菌总基因组 DNA 的提取参照 Zhou 等的方法 ${ }^{[26]}$. 采用针对细菌 16S rDNA 的特异性引物进行 PCR 扩增, 正向引物是 341f( $5^{\prime}$-CCTACGGGAGGCAGCAG-3') , 引物的 $5^{\prime}$ 端连有一个 $40 \mathrm{bp}$ 的 GC 夹; 反向引 物为 $518 \mathrm{r}\left(5^{\prime}\right.$-ATTACCGCGGCTGCTGG-3' ${ }^{[16]}$. PCR 采用 $25 \mu \mathrm{l}$ 反应体系, 组份为: $10 \times$ PCR 缓冲液, $25 \mathrm{mmol} / \mathrm{L} \mathrm{MgCl} 2,2.5 \mathrm{mmol} / \mathrm{L} \mathrm{dNTP}, 0.5 \mu \mathrm{mol} / \mathrm{L}$ 引物, $1.0 \mathrm{U}$ Taq 酶 (Takara) 和 $1 \mu \mathrm{l}$ 模板 DNA, 加无菌水补 足至 $25 \mu \mathrm{l}$. PCR 扩增反应在 ABI 公司的热循环仪 (Applied Biosystems Veriti ${ }^{\mathrm{TM}}$ Thermal Cycler) 中进行, 采用 降落 PCR 扩增程序: $94^{\circ} \mathrm{C}$ 预变性 $5 \mathrm{~min}, 94^{\circ} \mathrm{C}$ 变性 $30 \mathrm{~s}, 65 \sim 53^{\circ} \mathrm{C}$ ( 每个循环温度下降 $1^{\circ} \mathrm{C}$ ) 退火 $30 \mathrm{~s}, 72^{\circ} \mathrm{C}$ 延 伸 $30 \mathrm{~s}, 13$ 个循环; 采用 $53^{\circ} \mathrm{C}$ 的退火温度再进行 21 个循环; 最后 $72^{\circ} \mathrm{C}$ 延伸 $7 \mathrm{~min}$. PCR 结束后进行琼脂糖凝 胶电泳, 确定片段大小, 用图像分析软件拍照分析.

变性梯度凝胶电泳使用美国 CBS 公司电泳仪 (DGGE-2001) 进行, 使用 $8 \%$ 的聚丙烯酰胺变性胶(丙稀 酰胺: 双丙稀酰胺 $=37.5: 1)$, 变性梯度为 40\% 60\% (100\% 变性胶含有 $7 \mathrm{~mol} / \mathrm{L}$ 尿素和 40\% 去离子甲酰 胺). 电泳缓冲液为 $1 \times \mathrm{TAE}(20 \mathrm{mmol} / \mathrm{L}$ Tris, $10 \mathrm{mmol} / \mathrm{L}$ acetate, $0.5 \mathrm{mmol} / \mathrm{L}$ EDTA, pH 8.0 $) .60^{\circ} \mathrm{C}$ 恒压 $100 \mathrm{~V}$, 电泳 16 h. DGGE 胶用 SYBR GREEN I( 1:10000 稀释) 染色 15 30 min, 采用 Omegal0 ${ }^{\mathrm{TM}}$ 全自动多功能凝胶成 像分析系统拍照.

\section{6 样品的克隆建库}

根据 DGGE 结果, 选择 $1^{\#} 、 4^{\#} 、 7^{\#}$ 样品克隆建库, 使用细菌通用引物 27f( $5^{\prime}$-AGAGTTTGATCMTGGCTCAG-3') 和 $1492 \mathrm{r}$ (5'-GGTTACCTTGTTACGACTT-3') 扩增细菌的 $16 \mathrm{~S}$ rDNA. 反应体系 $(25 \mu \mathrm{l}): 2.5 \mu \mathrm{l} 10 \times$ buffer,

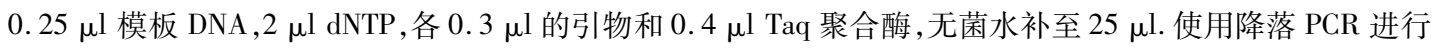
扩增, 程序如下: $94^{\circ} \mathrm{C}$ 预变性 $5 \mathrm{~min}, 94^{\circ} \mathrm{C}$ 变性 $45 \mathrm{~s}, 65 \sim 52^{\circ} \mathrm{C}$ ( 每循环下降 $0.5^{\circ} \mathrm{C}$ ) 退火 $45 \mathrm{~s}, 72^{\circ} \mathrm{C}$ 延伸 $90 \mathrm{~s}, 24$ 个循环; 采用 $52^{\circ} \mathrm{C}$ 的退火温度再进行 6 个循环; 最后 $72^{\circ} \mathrm{C}$ 延伸 $7 \mathrm{~min}$. 将 3 次 PCR 产物混合后通过 $1 \%$ 琼脂 糖凝胶电泳, 割胶后纯化, 立即进行 TA 克隆, 将纯化后的 PCR 产物连接到 pGEM-T Easy 载体( Promega) 上, 然后转化人大肠杆菌 Top 10 感受态细胞,构建克隆文库.

\section{7 测序和系统进化树分析}

每个文库随机挑选 100 个阳性克隆进行测序. 测序由上海美吉生物医药科技有限公司完成. 所得序列 使用 BioEdit (version 7.0.9) 剪切留取置信度最高的 750bp 序列. 利用 RDP 在线程序 Check-Chimera 对获得 的 16S rDNA 序列片段进行嵌合体 (Chimera) 检验, 并通过 BLAST (http://www. ncbi. nlm. nih. gov/blast) 进行 数据库比对, 去除嵌合体和叶绿体 (Chloroplast) 序列. 将相似性高于 $97 \%$ 的序列归为同一个操作分类单元 (operational taxonomic unit, OTU), 每一个 OTU 中选择代表性克隆子 (3 个文库中各选一个) 在 NCBI 数据库 中进行 BLAST 比对, 选择参比序列, 然后使用 MEGA 5.0 (Molecular Evolutionary Genetics Analysis, version 5.0 ) 软件, 根据 Jukes-Cantor 算法计算进化距离, 用最小进化距离法 (ME 法) 构建系统进化树. 进化树拓扑 学分析的置信值由 1000 次随机取样后, 经最大简约分析 (maximum parsimony analysis) 计算所得. 本研究所 
得到的 248 个细菌 $16 \mathrm{~S}$ rDNA 序列已上传到 GenBank 数据库, 登录号为 JX075268 JX075515.

\section{8 数据处理}

所得到的数据用统计软件 SPSS 17.0 进行单因素方差分析 (One way ANOVA), 以比较不同沉水植物生 态修复与无草对照点间差异的显著性. DGGE 结果用 GelCompar II 软件 (Applied Maths, Kortrijk, Belgium) 进 行分析, 以获得 DGGE 条带信息的矩阵, 计算各样品细菌群落的多样性指数, 并进行聚类分析. 克隆文库覆 盖度及多样性指数等用软件 SPADE (Chao and Shen, http://chao. stat. nthu. edu. tw/softwareCE. html) 进行计 算. 文库差异的显著性通过 Mothur 软件(版本 v1.24.0) 中的 - Libshuff 程序进行比较 ${ }^{[27]}$.

\section{2 结果}

\section{1 水质参数}

薄草处理、苦草处理与湖区无草对照之间 $\mathrm{pH}$ 无显著差异, 均值为 9.01 ; 无草对照点平均水温为 $23.47^{\circ} \mathrm{C}$, 分别比淔草处理和苦草处理低 0.70 和 $1.40^{\circ} \mathrm{C}$ (图 $2 \mathrm{~A}$ ). 种植沉水植物显著降低了水体的浊度和 SS 含量, 使水体的透明度提高了 $82 \%$, 但显著增加了水体中有机质的比例 (图 $2 \mathrm{~B} 、 \mathrm{C}$ ). 种植沉水植物也显著降 低了水体中 TP、TN 及 DTN 的浓度, 但对水体中 DTP 的影响不大 (图 2D、E). 种植菹草和苦草均使水体中 DO 浓度升高, 但与无草对照组之间差异不显著 (图 2F). 沉水植物的恢复显著降低了水体中的 Chl. a 的含量 ( 图 2G).

\section{2 细菌丰度}

北里湖无草对照点细菌丰度均值为 $2.96 \times 10^{6} \mathrm{cells} / \mathrm{ml}$, 种植淔草和苦草使细菌丰度分别降至 $2.27 \times 10^{6}$ 和 $2.51 \times 10^{6} \mathrm{cells} / \mathrm{ml}$, 但三者间的差异未达到显著水平 $($ 图 $2 \mathrm{H}$ ).

\section{3 细菌 PCR-DGGE 分析}

DGGE 结果显示无草对照 DGGE 条带数均值为 30 条, 䓚草处理和苦草处理的 DGGE 条带数均值分别为 40 条和 34 条, 且菹草处理与无草对照相比差异显著 (图 2I). 聚类分析表明在相似度为 $70 \%$ 的水平上, 无草 对照、菹草处理和苦草处理细菌群落分别形成 3 个明显不同的类群 (图 3). 根据 DGGE 结果计算出来的细菌 多样性指数也表明: 种植菹草和苦草可显著提高水体中细菌的 Shannon 指数 (图 $2 \mathrm{~J}$ ).

\section{4 克隆文库的分析}

3 个细菌 $16 \mathrm{~S} \mathrm{rDNA}$ 克隆文库去除嵌合体序列及 28 个来自硅藻门的 Chloroplast 序列 (均来自蕰草处理 的文库) 后, 共得到 248 个有效序列, 44 个 OTU (表 1). 3 个文库的覆盖度在 $77.8 \% \sim 95.6 \%$ 之间, 说明文库 的代表性比较高. 文库的 Chao1 指数数据表明, 种植水草后水体中细菌种类的丰富度有所增加, 但反映克隆文 库中 OTU 的丰度、均匀度等的综合指标的 Shannon 指数 $\left(H^{\prime}\right)$ 变化趋势不一(表 1). J -Libshuff 结果表明: 种植菹 草和苦草的处理组之间细菌群落差异不显著, 但两者均与无草对照组的细菌群落结构差异显著 (表 2).

\section{表 1 细菌克隆文库多样性比较}

Tab. 1 Comparison of bacterial diversity and library coverage estimations in the clone libraries

\begin{tabular}{cccccc}
\hline 克隆文库 & 克隆子数目 & OTU & $\begin{array}{c}\text { Chao1 指数 }{ }^{*} \\
(95 \% \text { 置信区间 })\end{array}$ & $H^{\prime}$ & 覆盖度 $/ \%$ \\
\hline 菹草处理 & 63 & 22 & $66.5(33.1,192.3)$ & 2.98 & 77.8 \\
苦草处理 & 94 & 22 & $31.4(24.5,57.9)$ & 2.44 & 87.2 \\
无草对照 & 91 & 18 & $19.2(18.1,28.4)$ & 2.59 & 95.6 \\
合计 & 248 & 44 & $94.6(61.0,194.3)$ & 3.22 & 90.7 \\
\hline
\end{tabular}

$*$ 代表无偏 Chaol 指数; $H^{\prime}$ 代表由无偏最大似然法估计值得到的 Shannon 指数.

\section{5 系统发育分析}

北里湖细菌由拟杆菌门 (Bacteroidetes)、病微菌门(Verrucomicrobia)、放线菌门 (Actinobacteria) 和变形菌 门(Proteobacteria) 中的 Alpha-、Beta-及 Gamma-proteobacteria 3 个纲组成. Bacteroidetes、Betaproteobacteria 和 Verrucomicrobia 是 3 个最主要的细菌门类, 分别占到 $42.9 \% 、 30.8 \%$ 和 $14.3 \%$ (图 4). 种植蕰草和苦草的围 


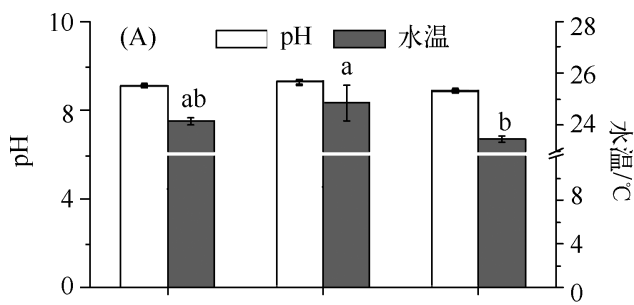

(F)
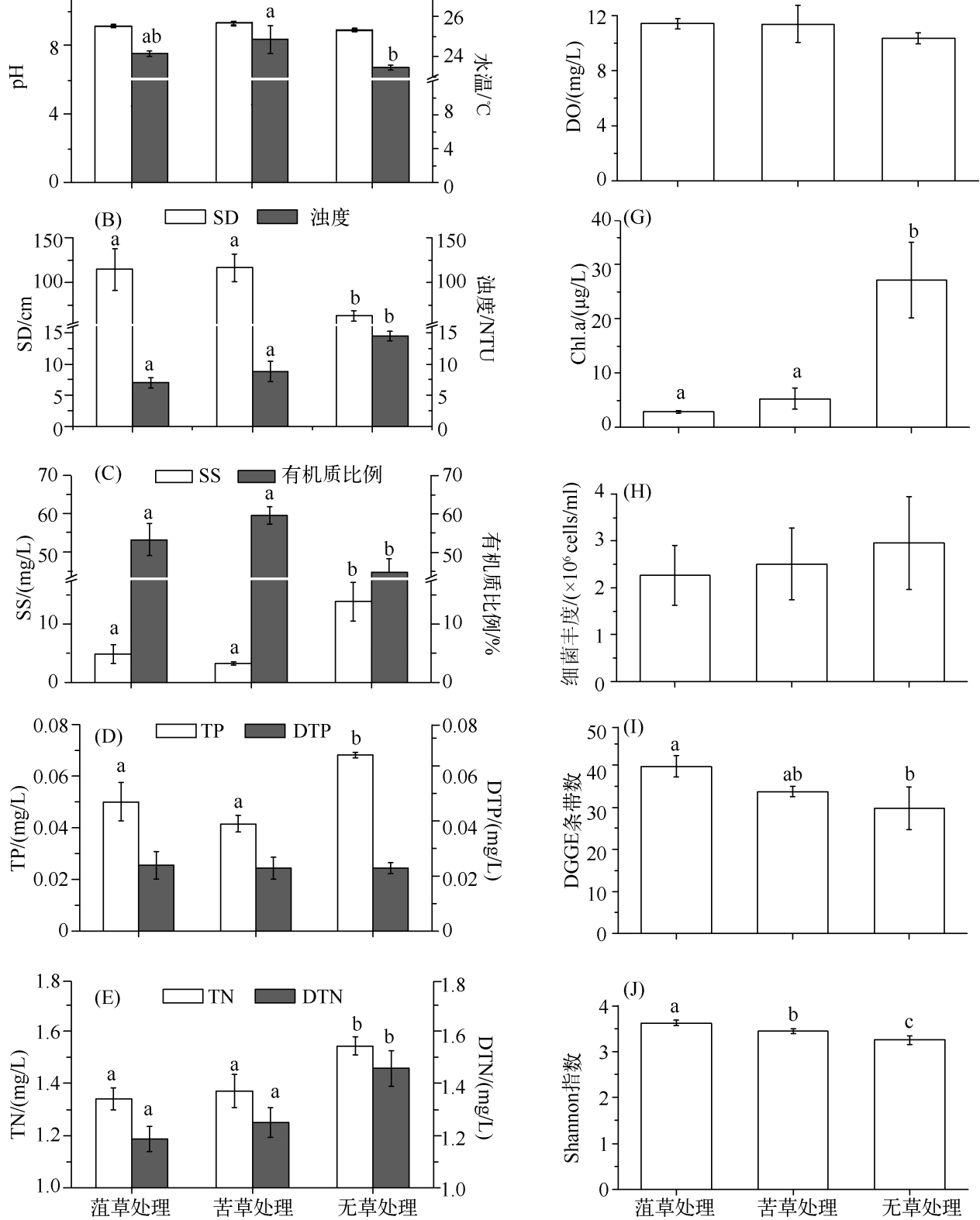

图 2 西湖不同处理围隔及湖区无草对照点主要的水质及生物参数比较 (数据为均值 \pm 标准差; 不同字母表示同一指标不同处理下差异显著 $(P<0.05))$

Fig. 2 Comparison of water quality and biological parameters among two kinds of ecological restorations and the control stations in West Lake

隔中 Bacteroidetes 所占的比例分别减少了 $30.2 \%$ 和 $37.6 \%$; Betaproteobacteria 所占的比例分别提高了 $21.6 \%$ 和 $28.8 \%$; Alphaproteobacteria 则由 $4.4 \%$ 提高到 $19.0 \%$ 和 $12.8 \%$. 种植菹草后 Verrucomicrobia 的比例大幅降 低, 而种植苦草对 Verrucomicrobia 的影响不大. 此外, 种植菹草的围隔中 Gammaproteobacteria 的比例提高了 $5.1 \%$, 并且浮霉菌门 (Planctomycetes) 的细菌也只发现存在于这种围隔中. 


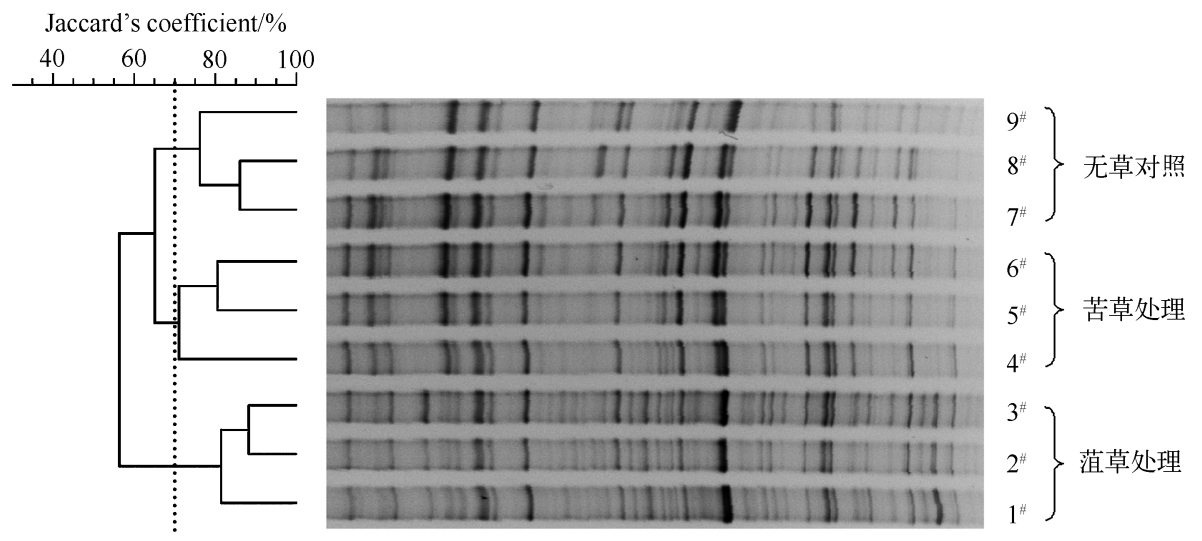

图 3 不同处理围隔中和湖区无草对照点细菌群落组成的 DGGE 图谱及聚类分析

Fig. 3 Bacterial community composition analyzed by DGGE profiles and cluster analysis of the samples

通过与已培养的细菌进行序列相似性比对 发现 ${ }^{[28]}, 248$ 序列与已培养的细菌的相似性在 $82.2 \% \sim 100 \%$ 之间, 其中相似性大于 $97 \%$ 的序 列占到 $50.4 \%$. 细菌 $16 \mathrm{~S} \mathrm{rDNA}$ 的系统发育树表 明,3 个文库中共有 $70.2 \%$ (174 个) 的序列属于 15 个已知的典型淡水细菌类群 ${ }^{[29-32]}$, 如属于 Betaproteobacteria 的 Rhodoferax sp. BAL47、 LiUU-5-340.2、P. necessarius、PRD18A09等; 属于 Alphaproteobacteria 的 GOBB3-C201、LiUU-9-283. 2 等; 属于 Bacteroidetes 的 PRD01001B 等; 属于 Verrucomicrobia 的 CL0-14 等 (图 5). 其中属于 Rhodoferax sp. BAL47、CL0-14、GOBB3-C201 和 PRD01001B 这 4 个类群的细菌序列最多, 分别 表 2 细菌群落结构差异性显著性的 $\int$-Libshuff 分析

Tab. 2 f-Libshuff comparisons of the heterogeneity of the three bacterial clone libraries

\begin{tabular}{llcc}
\hline 克隆文库 & 比较 & $P$ 值 & 显著性 ${ }^{*}$ \\
\hline 菹草处理 vs. 苦草处理 & $\mathrm{XY}$ & 0.1813 & 不显著 \\
& $\mathrm{YX}$ & 0.4202 & \\
菹草处理 vs. 无草对照 & $\mathrm{XY}$ & 0.6952 & 显著 \\
& $\mathrm{YX}$ & 0.0001 & \\
苦草处理 vs. 无草对照 & $\mathrm{XY}$ & 0.0676 & 显著 \\
& $\mathrm{YX}$ & 0.0001 & \\
\hline
\end{tabular}

*当相比较的两个文库的 $P$ 值有一个小于 0.0083 $(0.05 / 6=0.0083)$ 时, 表示两者差异显著. 为 $77 、 30 、 24$ 和 22 个. Rhodoferax sp. BAL47 类 群的克隆子最相近的菌株是最近分离纯化自捷克 Rimov 水库的两个菌株 Limnohabitans planktonicus II-D5 $^{\mathrm{T}}$ 和 Limnohabitans parvus II-B4 ${ }^{\mathrm{T}[33]}$, 属于其它 3 个类群的克隆子没有相似性大于 $97 \%$ 的相应菌株.

\section{3 讨论}

\section{1 沉水植物生态修复对水体中细菌多样性的影响}

氮、磷及有机碳等是细菌增殖的限制因素, 通常氮、磷浓度的升高可促进湖泊中细菌的增殖, 但水体营 养盐的过度升高也会造成沉水植物的消亡、微生物多样性下降等生态环境的恶化,最终导致湖泊生态系统 受损 ${ }^{[34-37]}$. 本研究表明, 种植沉水植物后水体中的细菌数量有所下降, 但是细菌的 DGGE 条带数有所增加, 并且表征细菌多样性的 Shannon 指数也显著高于无草对照水域 (图 2), 这与毛杰等研究的结果一致 ${ }^{[23]}$.

围隔实验发现, 进行菹草和苦草生态修复可显著降低水体中 TN 、TP 浓度及 Chl. a 的含量, 同时降低水 体的浊度及悬浮物的浓度, 显著提高水体的透明度 (图 2), 使生态系统由以浮游植物为主的浊水态系统转变 为以沉水植物为优势的清水态系统. 沉水植物的生长可吸收大量的营养盐, 同时抑制沉积物中营养盐的释 放, 而水体中氮、磷等营养盐的降低可能是导致围隔中细菌丰度降低的主要原因. 由于竞争和化感作用, 沉 水植物可能抑制浮游植物的生长, 导致处理组叶绿素含量远低于无草对照组, 而浮游植物群落可以显著影 响浮游细菌的多样性 ${ }^{[30]}$. 其次, 沉水植物的生长增加了水体微环境的异质性, 为细菌提供更加多样的生态 位, 这可能是生态修复后细菌多样性增加的另一个主要原因. 此外, 种植沉水植物后水体中有机质比例显著 

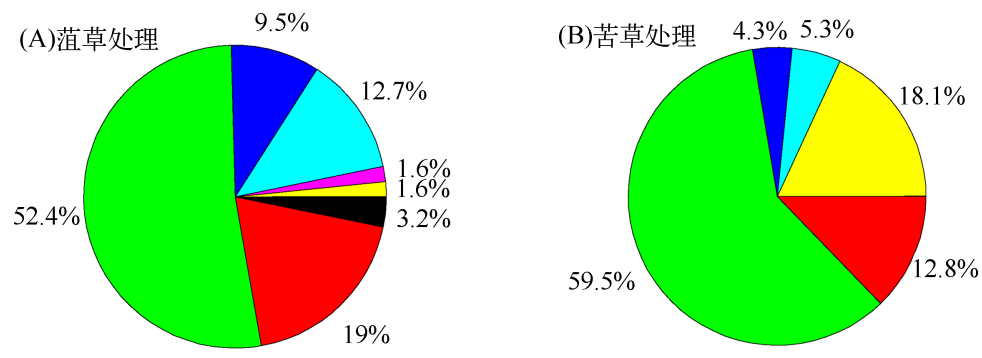

(C)无草处理
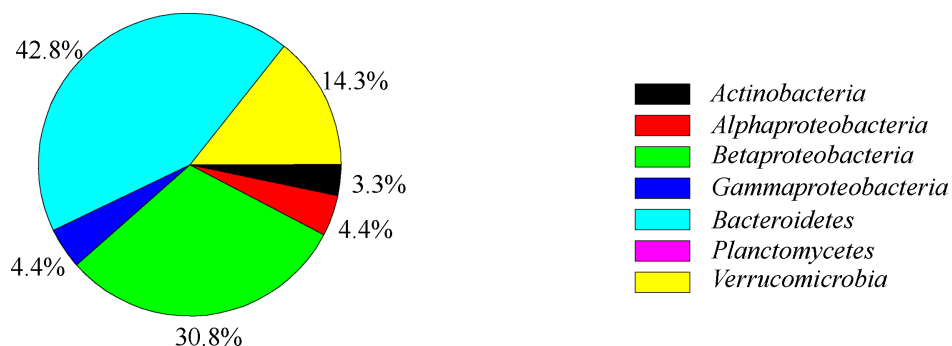

图 4 不同沉水植物处理下细菌种类组成的百分比

Fig. 4 Relative abundance of bacterial phylogenetic groups in the studied clone libraries

高于湖区无草对照 (图 2C), 这暗示沉水植物降低营养盐和浮游植物生物量的同时, 自身释放一定的溶解性 有机碳 (DOC). 而研究表明 DOC 对细菌群落及其多样性有一定的调控作用 ${ }^{[9,38]}$.

\section{2 沉水植物生态修复对水体中细菌群落结构的影响}

革兰氏阳性菌 Bacteroidetes (即以前的Cytophaga-Flexibacter-Bacteroides, CFB) 和革兰氏阴性菌 $\alpha$ - $\beta$-proteobacteria 是富营养化的淡水湖泊生态系统中最为丰富的细菌菌群. 研究表明, 沉水植物的存在可显著改变 水体中细菌的群落组成 ${ }^{[20,39]}$. 本实验发现, 沉水植物生态修复后水体中的 Bacteroidetes 比例大为降低, 而 $\alpha$ - 、 $\beta$-proteobacteria 比例迅速上升 (图 4). 这种细菌类群比例的变化, 主要表现为少数典型淡水类群中克隆子数 量的增减和部分新 OTU 的产生 (图 5、6). 例如, 无草对照点湖水中属于 Bacteroidetes 的一个 OTU (代表克隆 子为: XH-4-B-80, 共有 21 个克隆子, 图 5) 就占到 Bacteroidetes 中克隆子总数的 53.8\%, 与此 OTU 最相似的 序列 clone E4 (HQ853002) 来自富营养化的洱海. 而经沉水植物修复后的水体中此 OTU 的细菌几乎消失. Bacteroidetes 数量的减少并伴随 $\alpha$-和 $\gamma$-proteobacteria 数量的增加可能是水质改善的表现 ${ }^{[40-41]}$.

细菌群落结构的变化是其对环境变化的适应, 也与其功能相一致. 沉水植物修复可通过抑制沉积物再 悬浮和抑制浮游植物的过度繁殖、释放可溶性有机物等, 改变局域水体的水质, 甚至生态系统的类型 (浊水 型转变为清水型), 最终也影响到水体中细菌的多样性、群落组成及生态学功能. 例如, 湖泊中 $\alpha$-proteobacteria 被认为在低营养盐环境中更有竞争力, 并且它们有降解复杂有机复合物 (可能来自沉水植物的释放或降解) 的能力, 而 Bacteroidetes 常与藻类释放的有机物降解关系密切 ${ }^{[30,42]}$. 虽然本实验发现蕰草和苦草对水体中细 菌多样性和细菌群落组成的影响不完全一致 (图 4、5、6), 但是这有可能与实验时这两种植物所处的生长时 期和覆盖度不同有关. 采样时菹草生长已经达到鼎盛期, 覆盖度达到了 $100 \%$; 而此时苦草刚处于生长初期, 覆盖度也只有 $50 \%$ 左右. 不同种类的沉水植物或不同组合的沉水植物对水体中细菌的影响是否相同, 仍需 要更多的实验数据加以揭示.

综上所述, 沉水植物生态恢复不仅可以提高水质, 也可以提高水体中细菌的多样性, 改变水体中细菌的 群落组成, 使之向更加健康的方向发展. 在控源截污的基础上, 进行沉水植物生态恢复与维持, 并配以适当 的工程措施和管理, 可加快湖泊生态修复进程.

致谢: 感谢朱广伟研究员、赵林林、薛庆举、杨尚等在采样及水样化学分析中给予的帮助. 


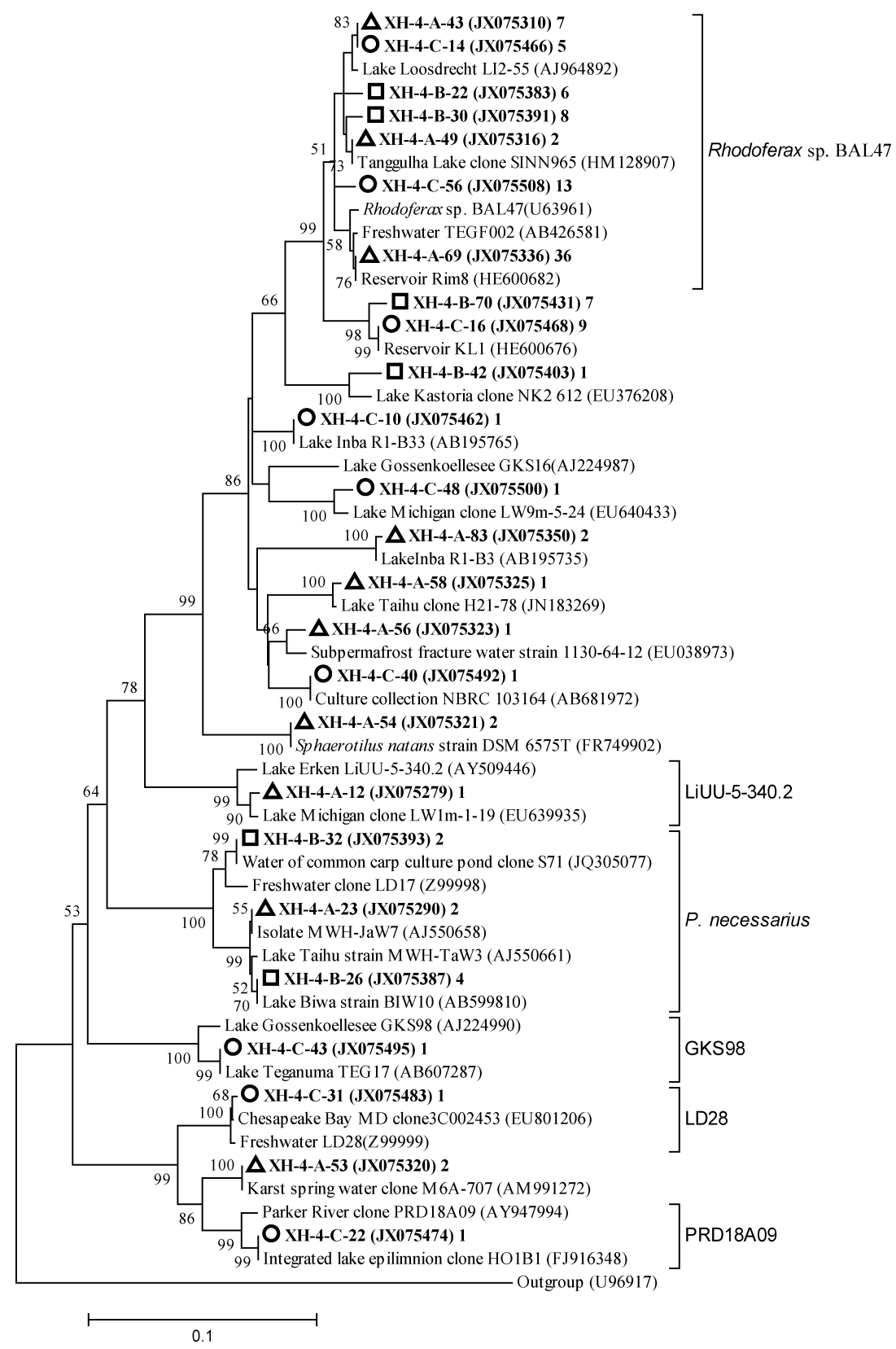

图 5 Betaproteobateria 基于 $16 \mathrm{~S} \mathrm{rDNA}$ 的系统发育树(本研究所获得的克隆子加粗显示. 克隆子前面的符号 表示不同的文库:菹草处理 $(\bigcirc)$, 苦草处理 $(\triangle)$, 无草对照 $(\square)$. 克隆子后括号内为其 GenBank 登录号, 最后面为同一文库中属于同一 OTU 的克隆子数目. 从 GenBank 数据库获得的相似序列的生境置于其登 录号之前. 中括号后为典型淡水浮游细菌类群,下同)

Fig. 5 Minimum evolution trees inferred by analysis of partial 16S rDNA sequences obtained from the tree studied clone libraries shown for Betaproteobacteria ( The numbers of clones in each OTU ( shown as bold) are given in parentheses. The symbols before each OTU donate its origin: Potamogeton crispus treatment $(\bigcirc)$, Vallisneria natans treatment $(\triangle)$ and the control $(\square)$. The habitats of the most related sequences are given before their GenBank accession numbers. The reported typical freshwater bacterial clusters are shown after corresponding brackets, the same below) 


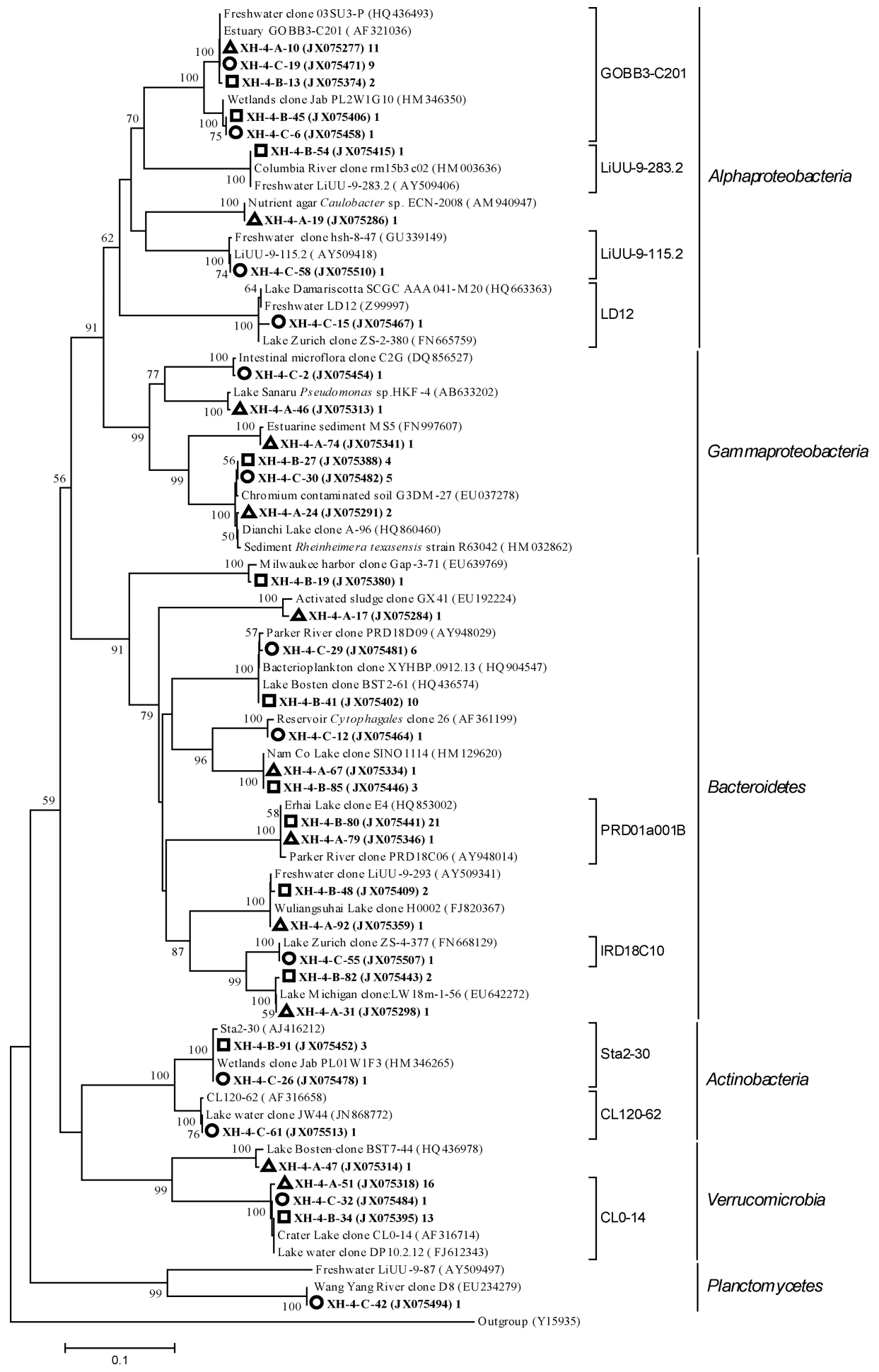

图 6 除 Betaproteobateria 外细菌门类基于 $16 \mathrm{~S} \mathrm{rDNA}$ 的系统发育树

Fig. 6 Minimum evolution trees inferred by analysis of partial 16S rDNA sequences obtained from the tree studied clone libraries shown for the other phyla except Betaproteobacteria 


\section{4 参考文献}

[ 1 ] Le C, Zha Y, Li Y et al. Eutrophication of lake waters in China: cost, causes, and control. Environment Management, $2010,45(4)$ : 662-668.

[ 2 ] Smith VH, Schindler DW. Eutrophication science: where do we go from here? Ecology and Evolutionary Biology, 2009, 24(4) : 201-207.

[ 3 ] Qin B. Lake eutrophication: Control countermeasures and recycling exploitation. Ecological Engineering, 2009, 35(11): 1569-1573.

[4] 种云霄, 胡洪营, 钱 易. 大型水生植物在水污染治理中的应用研究进展. 环境污染治理技术与设备, 2003,4(2): $36-40$.

[ 5 ] 秦伯强. 长江中下游浅水湖泊富营养化发生机制与控制途径初探. 湖泊科学,2002,14(3):193-202.

[ 6 ] 秦伯强. 长江中下游湖泊富营养化发生机制与控制对策. 中国科学院院刊,2007,22(6):503-505.

[ 7 ] Cotner JB, Biddanda BA. Small players, large role: microbial influence on biogeochemical processes in pelagic aquatic ecosystems. Ecosystems, $2002, \mathbf{5}(2): 105-121$.

[ 8 ] Ciurli A, Zuccarini P, Alpi A. Growth and nutrient absorption of two submerged aquatic macrophytes in mesocosms, for reinsertion in a eutrophicated shallow lake. Wetlands Ecology and Management, 2009, 17 (2) : 107-115.

[ 9 ] Rooney N, Kalff J. Submerged macrophyte-bed effects on water-column phosphorus, chlorophyll a, and bacterial production. Ecosystems, 2003, 6(8): 797-807.

[10］吴根福,杨志坚,周雪平等. 杭州西湖水体中异养细菌生长的限制因子. 应用生态学报,2003,14(8):1343-1346.

[11] 董百丽, 秦伯强, 龚志军等. 三种沉积物改良措施比较及其对苦草生长的影响. 生态学杂志, 2011, 30 (12): 2726-2731.

[12] 李文红,施积炎. 西湖沉积物中解磷菌的分离纯化及其解磷能力. 应用生态学报,2006,17(11):2112-2116.

[13] 吴根福,吴 洁. 杭州西湖水域微生物的生态调查. 水生生物学报,2000,24(6):589-596.

[14] 吴根福,虞左明, 吴 洁等. 杭州西湖水域可培养异养细菌的群落多样性.生物多样性,2003,11(6):467-474.

[15] Amann RI, Ludwig W, Schleifer KH. Phylogenetic identification and in situ detection of individual microbial cells without cultivation. Microbiological Reviews, 1995, 59(1) : 143-169.

[16] Muyzer G, De Waal EC, Uitterlinden AG. Profiling of complex microbial populations by denaturing gradient gel electrophoresis analysis of polymerase chain reaction-amplified genes coding for 16S rRNA. Applied and Environmental Microbiology, 1993, 59(3): 695-700.

[17] 吴 金䍃万艳,杨 虹. 太湖梅梁湾冬季浮游细菌的多样性.生态学杂志,2006,25(10):1196-1200.

[18] 奚万艳, 吴 金, 叶文瑾等. 太湖梅梁湾水域蓝藻水华前与水华末期细菌群落结构的变化. 应用与环境生物学报, 2007,13 ( 1 ):97-103.

[19] 邢 鹏, 孔繁翔,高 光. 太湖浮游细菌种群基因多样性及其季节变化规律. 湖泊科学,2007,19(4):373-381.

[20] Wu QL, Zwart G, Wu J et al. Submersed macrophytes play a key role in structuring bacterioplankton community composition in the large, shallow, subtropical Taihu Lake, China. Environmental Microbiology, 2007, 9(11) : 2765-2774.

[21 ] Tang X, Gao G, Chao J et al. Dynamics of organic-aggregate-associated bacterial communities and related environmental factors in Lake Taihu, a large eutrophic shallow lake in China. Limnology and Oceanography, 2010, 55(2) : 469-480.

[22] 冯 胜, 高 光, 朱广伟等. 基于 $16 \mathrm{~S}$ rDNA-DGGE 和 FDC 技术对富营养化湖泊不同生态修复工程区细菌群落结构 的研究. 应用与环境生物学报, 2007,13(4):535-540.

[23] 毛 杰,邢 鹏, 刘正文. 惠州西湖沉水植被修复对浮游细菌群落结构的影响. 水生态学杂志,2011,32(3):26-31.

[24] 金相灿,屠清瑛. 湖泊富营养化调查规范:第 2 版. 北京:中国环境科学出版社,1990.

[25] 高 光, 肖 琳, 杨柳燕等. 环境微生物实验技术. 北京: 中国环境科学出版社,2004:103-107.

[26] Zhou J, Bruns MA, Tiedje JM. DNA recovery from soils of diverse composition. Applied and Environmental Microbiology, $1996,62(2): 316-322$.

[27] Schloss PD, Westcott SL, Ryabin T et al. Introducing mothur: open-source, platform-independent, community-supported software for describing and comparing microbial communities. Applied and Environmental Microbiology, 2009, 75(23): $7537-7541$. 
[28] Kim OS, Cho YJ, Lee K et al. Introducing EzTaxon-e: a prokaryotic 16S rRNA gene sequence database with phylotypes that represent uncultured species. International Journal of Systematic and Evolutionary Microbiology, 2012, 62: 716-721.

[29] Crump BC, Hobbie JE. Synchrony and seasonality in bacterioplankton communities of two temperate rivers. Limnology and Oceanography, 2005, 50(6): 1718-1729.

[30] Eiler A, Bertilsson S. Composition of freshwater bacterial communities associated with cyanobacterial blooms in four Swedish lakes. Environmental Microbiology, 2004, 6(12): 1228-1243.

[31] Hahn MW. Isolation of strains belonging to the cosmopolitan Polynucleobacter necessarius cluster from freshwater habitats located in three climatic zones. Applied and Environmental Microbiology, 2003, 69(9) : 5248-5254.

[32] Zwart G, Crump BC, Agterveld MPK-V et al. Typical freshwater bacteria: an analysis of available 16S rRNA gene sequences from plankton of lakes and rivers. Aquatic Microbial Ecology, 2002, 28: 141-155.

[33] Kasalický V, Jezbera J, Šimek K et al. Limnohabitans planktonicus sp. nov. and Limnohabitans parvus sp. nov. , planktonic betaproteobacteria isolated from a freshwater reservoir, and emended description of the genus Limnohabitans. International Journal of Systematic and Evolutionary Microbiology, 2010, 60(12) : 2710-2714.

[34] Vrede K. Nutrient and temperature limitation of bacterioplankton growth in temperate lakes. Microbial Ecology, 2005,49 (2) : 245-256.

[35] Morris DP, Lewis WM. Nutrient limitation of bacterioplankton growth in Lake Dillon, Colorado. Limnology and Oceanography, 1992, 37(6): 1179-1192.

[36] Van Der Gucht K, Vandekerckhove T, Vloemans N et al. Characterization of bacterial communities in four freshwater lakes differing in nutrient load and food web structure. FEMS Microbiology Ecology, 2005, 53(2) : 205-220.

[37] 冯 胜, 秦伯强, 高 光. 细菌群落结构对水体富营养化的响应. 环境科学学报, 2007,27(11): 1823-1829.

[38] Hitchcock JN, Mitrovic SM, Kobayashi T et al. Responses of estuarine bacterioplankton, phytoplankton and zooplankton to dissolved organic carbon (DOC) and inorganic nutrient additions. Estuaries and Coasts, 2010, 33(1) : 78-91.

[39] Van Der Gucht K, Sabbe K, De Meester L et al. Contrasting bacterioplankton community composition and seasonal dynamics in two neighbouring hypertrophic freshwater lakes. Environmental Microbiology, 2001, 3(11): 680-690.

[40] Dirnitriu PA, Pinkart HC, Peyton BM et al. Spatial and temporal patterns in the microbial diversity of a meromictic soda lake in Washington State. Applied and Environmental Microbiology, 2008, 74(15): 4877-4888.

[41] 孙金金金, 刘惠荣, 冯福应等. 乌梁素海富营养化湖区浮游细菌多样性及系统发育分析. 生物多样性, 2009, 17 (5): $490-498$.

[42] Newton RJ, Jones SE, Eiler A et al. A guide to the natural history of freshwater lake bacteria. Microbiology and Molecular Biology Reviews, 2011, 75(1): 14-49. 